\title{
Challenges and Prospects for Teaching Practice in the Zimbabwe Open University: Learning from Experiences in the First Semester 2016 Teaching Practice Supervision Exercise in Masvingo, Bulawayo, Matabeleland North and Matabeleland South
}

\author{
Maxwell C.C. Musingafi \\ Department of Development Studies, Zimbabwe Open University, Masvingo Region \\ Tsitsi Dhliwayo \\ Department of Techer Development, Zimbabwe Open University, National Centre \\ Wilson. Namusi \\ Department of Physical Education, Zimbabwe Open University, Harare Region
}

\begin{abstract}
In this qualitative study, we examine the experiences of the Zimbabwe Open University Post-Graduate Diploma in Education (ZOU PGDE) in-service student teachers, their academic supervisors and host schools supervisors in Masvingo, Bulawayo, Matabeleland North and Matabeleland South provinces. The major aim of the study is to establish challenges and prospects for the teaching practice programme to map up the way forward for teaching professionalization through distance and open learning in Zimbabwe. Teaching practice simply represents the range of experiences to which student teachers are exposed when they work in classrooms and schools. All over the world, teaching practice has been made an integral part of teacher training as it gives student teachers hands on experience in the actual teaching and learning environment. Guided by this background knowledge and Adult Learning theories, we explore the experiences of Intake 14 Masvingo Region ZOU PGDE student teachers through primary observations, teaching practice supervision reports and impressions of academic supervisors from the January - March 2016 teaching practice supervision session. The paper reaffirms Marais and Meier's (2004) observation that teaching practice is a challenging but important part of teacher training. We established that in the current Zimbabwe Open University context, teaching practice effectiveness could easily be diminished or eroded by a range of challenges. Some of such challenges include geographical distance, uneven levels of supervisors and mentors expertise, a wide-ranging lack of resources as well as a lack of discipline among a wide cross-section of learners and educators.
\end{abstract}

Keywords: Teaching practice, mentor, challenges, prospects, experiences, supervision, student teacher, professional development.

DOI: $10.7176 / \mathrm{JEP} / 10-7-09$

Publication date:March $31^{\text {st }} 2019$

\section{Introduction}

In this qualitative study we examine the experiences of the Zimbabwe Open University Post-Graduate Diploma in Education (ZOU PGDE) in-service student teachers, their academic supervisors and host schools supervisors in Masvingo, Bulawayo, Matabeleland North and Matabeleland South provinces. The major aim of the study is to establish challenges and prospects for the teaching practice programme so as to map out the way forward for teaching professionalization through distance and open learning in Zimbabwe. After defining some key concepts and a brief orientation and statement of the problem, we look at the theoretical and conceptual framework guiding us in the discussion in this paper. This is followed by methodology and discussion of findings. We close the discussion by drawing some conclusions and recommendations as determined by our findings in this study.

\section{Terminology}

Before we get deep into the discussion in this paper, it is important that we define some key concepts: Supervision, school-based supervisors, teaching practice and professional development. In this paper, supervision refers to the act of assisting and assessing student teachers' performance. Its main concern is the improvement of classroom practice for the benefit of students, regardless of what else may be entailed. School-based supervisors include not only those who use the term in their title, but also school heads, deputy heads and all those who monitor the work of other teachers and help them to improve their performance at school level. Among these supervisors, we find the student mentor. A mentor can simply be described as a teacher, guide, counsellor, sponsor or facilitator. Ehrich and Hansford (1999) see the generic meaning of a mentor as a 'father' figure who sponsors, guides and instructs 
a younger individual who is known as a protégé. Teaching practice is a form of work-integrated learning that is described as a period of time when student teachers are working in the school to receive specific in-service training in order to apply theory in practice (Kiggundu and Nayimuli, 2009). Generally, the concept of professional development refers to the growth of practitioners (teachers) in their profession. This is defined by Villegas-Remers (2003: 12) as "a long-term process that includes regular opportunities and experiences planned systematically to promote growth and development in the profession".

\section{Orientation and Statement of the Problem}

As observed by Musingafi and Mafumbate (2014), teaching practice has been an integral component of teacher training since time immemorial. Several authors argue that teaching practice gives student teachers experience in the actual teaching and learning environment ((Ngidi and Sibaya, 2003; Marais and Meier, 2004; Perry, 2004). Teaching practice thus serves as an introduction to the realities of the situation in the teaching profession (Musingafi and Mafumbate (2014). As such, teaching practice creates a mixture of anticipation, anxiety, excitement and apprehension in the student teachers as they commence their teaching practice (Manion, Keith, Morrison and Cohen, 2003; Perry, 2004). But what does the term teaching practice mean?

Musingafi and Mafumbate (2014) summarise teaching practice as the practical component of all teacher training and development programmes the world over, however, known by different but related terms: the practice teaching, student teaching, teaching practice, field studies, infield experience, school based experience, practicum or internship (Taneja, 2000). Musingafi and Mafumbate (2014) conclude that the term teaching practice has three major connotations: the practicing of teaching skills and acquisition of the role of a teacher; the whole range of experiences that students go through in schools; and the practical aspects of the course as distinct from theoretical studies. Thus, as observed by Marais and Meier (2004), teaching practice represents the whole range of experiences to which student teachers are exposed when they work in classrooms and schools.

Teaching practice has not only been found to be challenging, but also an important part of teacher training. More so in developing countries, where the effectiveness of the teaching practice can be eroded by a range of challenges including geographical distance, low and uneven levels of teacher expertise, a wide-ranging lack of resources as well as a lack of discipline among a wide cross-section of learners and educators. These challenges, if not addressed, may affect student teachers' performance during teaching practice and may in the long run affect their perception of the teaching profession (Quick and Sieborger, 2005).

According to Musingafi and Mafumbate (2014), the aims of teaching practice are to provide opportunities for student teachers to integrate theory and practice, work collaboratively with, and learn from experienced teachers. In the ideal situation, student teachers should observe subject teachers at work to learn about teachers' skills, strategies and classroom achievements (Ibid). These student teachers also evaluate their own teaching experiences through discussions with teachers and lecturers; and through self-reflection and implementation of a variety of approaches, strategies and skills.

Menter (1989) notes that there has been a shift in the literature from the concept of traditional teaching practice (associated with an apprenticeship model) to the concept of field/school experience (associated with an experiential model). Lave and Wenger (1991) point out that however way it may be envisaged, the notion of teaching practice is entrenched in experience-based learning initiated by Dewey (1938), Vygotsky's (1978) social cognitive theory, and founded in the premise of situated learning. Consequently as suggested by the South African Norms and Standards for Educators (Republic of South Africa, 2000:12), teaching practice is meant to provide for the authentic context within which student teachers are exposed to experience the complexities and richness of the reality of being a teacher.

Teaching Practice has been a major and central component of both pre-service and in-service teacher education in Zimbabwe. Musingafi and Mafumbate (2015) observe that at independence in 1980 student teachers were treated as apprentices and they taught under the supervision of experienced teachers. This, however, changed in 1982, because of the high demand for teachers in the country. The situation forced the government to engage student teachers as full-time teachers with classes to themselves (Musingafi and Mafumbate, 2014).

As the teacher availability improved in the late 1990s student teachers were again placed under the guidance and mentorship of qualified and experienced professionals. Since then the 2-5-2 teacher-training model is used in teacher training colleges in Zimbabwe. During the first two terms, student teachers are in residence at the training college. They then spend five school terms doing teaching practice at a host school. The last two school terms they go back to the training college for preparation of their final examinations (Musingafi and Mafumbate, 2014).

In fact, open and distance (ODL) has played a significant role in teacher education since the United Nations and Works Agency (UNRWA / UNESCO) Institute of Education was set up in the 1960s. As seen in the Zimbabwe Integrated Teacher Education (ZINTEC) programme (1981-1988) that trained secondary school leavers on the job as primary school teachers, early programmes addressed crises by providing qualified teachers to marginalised and disadvantaged communities. The rationale for these ODL / in-service programmes has been based on crisis management or simply geographical challenges like accessibility and dispersion (Guyana, Nepal, Indonesia, the 
Caribbean and Pacific); high population volume (China and Pakistan); supporting curriculum reform and teacher upgrading (Latin America); redressing inequalities in post-colonial nations (Zimbabwe and South Africa); reconstruction in the teaching service (Uganda); and reaching marginalised groups such as refugees (Sudan).

A new peculiar challenge has now arisen in Zimbabwe: the rapidly increasing degreed secondary school teachers from the universities. These teachers have subject specific content but lack the professional and theoretical underpinnings for teaching and delivering content. To cover this gap the University of Zimbabwe introduced the Graduate Certificate in Education but it failed to accommodate the influx of degreed teachers in secondary schools as it enrolled a very small number of these degreed teachers. The Zimbabwe Open University then filled in this gap when it introduced the Post Graduate Diploma in Education (PGDE) in 2005 starting with a complement of 89 students. Since then, the numbers of degreed PGDE students have been rapidly increasing. By 2016 the university has a complement of 1560 PGDE students. With this growing number of in-service degreed student teachers, it is obvious that the university faces both challenges and opportunities in the management of teaching practice for the PGDE programme. In this paper, we thus seek to establish challenges and prospects for the teaching practice programme so as to map up the way forward for teaching professionalization through distance and open learning in Zimbabwe.

\section{Theoretical and Conceptual Framework}

From both a theoretical and conceptual perspective, this paper is influenced and guided by a number of social theories, among them the Adult Learning Theory; Social Cultural Practices; and Apprentice Model. These conceptual and theoretical frameworks help in shaping recommendations at the end of the paper.

\subsection{Adult Learning Theory}

Hansford et al. (2003) believe that the conceptual framework behind teaching practice and mentoring of student teachers is better known as adult learning theories. For them dominant adult learning theories, include Brookfield's theory of adult learning (1986); Daloz's theory of adult learning (1986); Kolb's theory of experiential learning (1984); and Schön's theory of reflection on learning (1987). The major argument of these theories is that learning is effective when student teachers are both supported and challenged by their educational environment. This line of thinking is well pronounced in cognitive skill psychology where emphasis is on how skill acquisition can be assisted through various forms of "coaching". According to Sloboda (1986: 32-33) "real life skills are usually learnt with the aid of some form of coaching". He further argues that "knowledge of what your actions achieved" is "essential to skill acquisition." This is the backbone of Tomlinson's (1995: 13) statement:

The acquisition of practical capability requires cycles of plan-attempt-feedback-replan, a process which when done with the same action unit tends to produce a gradual tuning that makes it accurate, economical and intuitive.

For Daloz's (1986) model student growth as a teacher has to be located within a context of support and challenge. He believes that where support is low there is little opportunity for any challenge to occur sometimes resulting in the student withdrawing from the mentoring relationship. If support is high, new knowledge and new images of teaching become possible for the student.

\subsection{Socio Cultural Perspectives}

Vygotsky's (1987) socio cultural perspective has also been a significant influence on the theoretical underpinning of teaching practice and mentoring. Vygotsky believes that human activities are rooted in social participation and learned not in isolation, but with the assistance of others. Social participation is thus seen as an important influence on the learning potential of school-based mentoring.

\subsection{Apprenticeship Model}

The Apprenticeship Model is the context within which a more experienced person works with a less experienced person. The roots of mentoring is thus located within the apprenticeship system. Lave and Wenger (1991), see apprenticeship as central to learning. They incorporate a number of theories, focusing not on individual cognitive processing, but on the whole person and the context and culture in which they learn. Lave and Wenger perceive learning as a process of participation in "communities of practice". In this process, the learner evolves over a period of time from peripheral participation to a position of increased engagement with the community they are within. Eventually the learner moves towards full participation, and in doing so absorbs the practice of the community.

Following their view of situated learning Lave and Wenger (1991: 53) also suggest that learning involves a learner becoming a different person with respect to "the possibilities enabled by these systems of relation." They believe that "to ignore this aspect of learning is to overlook the fact that learning involves the construction of identities." They also see learning as cultural, with the culture of the individual determining the way in which they see and interpret their experiences, and how students see themselves as teachers. 


\section{Research Methodology}

This study is qualitative based on document analysis; observations and experiences of ZOU Academic teaching practice supervisors for the January - May semester (authors of this paper were part of this team); and unstructured discussions with ZOU regional directors, school headmasters and students on teaching practice in Masvingo, Bulawayo, Matabeleland North and Matabeleland South. This triangulation of data collection instruments ensured credibility and trustworthiness of findings and conclusions of the study.

\section{Findings}

As per the purpose of this study, the findings are divided into challenges and prospects / opportunities for teaching practice in the Zimbabwe Open University. We start by looking at the challenges witnessed during the supervision exercise. We do not however, particularise these challenges to regions where they were more pronounced, we simply generalise the findings for ethical considerations.

\subsection{Challenges}

This study established several challenges for teaching practice in the Zimbabwe Open University. Some of the challenges include geographical distance, uneven levels of supervisors and mentors expertise, a wide-ranging lack of resources as well as a lack of discipline among a wide cross-section of learners and educators.

The field is highly competitive. With a background of negative publicity in the past few years, obviously ZOU has a big perceptual challenge to deal with. People and other authorities look down upon ZOU and do not believe that ZOU delivers until we prove them wrong. Traditional teachers' colleges and conventional universities were also in the field supervising their students on teaching practice. Students themselves were thus exposed to comparison in terms of their institution brand, visibility, reputation, quality of the programme and supervising academics, types of the vehicles supervisors were travelling in. Universities seemed to have an edge over teachers' colleges because their academic teams had academic doctors and professors. The number and quality of visits by an institution influence the heads and their teachers' impression on the programme offered by the institution, especially when the academic supervisors shared their findings or supervision reports with the head or the mentor.

In remote districts like Mwenezi, Chiredzi and Binga road network is extremely poor and the schools were very far apart to the extent that university supervisors spent most of their time travelling to these schools. Geographic features and the absence of standard roads in most of our rural areas (mountainous, dongas, streams and rivers without bridges, bumpy and stony roads) demanded use of 4 by 4 vehicles or rough terrain cruisers like land cruisers. All competing institution had high rider vehicles. The only evident difference was the type and model of the vehicle and that all other vehicles were branded and written name of their institution plus inscriptions like 'Teaching Practice' or something to that effect except for ZOU vehicles.

The Public Service Commission rationalisation of schoolteachers' deployment affected many students on teaching practice. Some student teachers were transferred to new schools and some contracts for those on closed contracts were not renewed. The transferred and dismissed students were difficult to locate because most of them did not communicate with the region about this development. When finally these students were located most of their documents were not up to standard due to this disturbance. Some of the dismissed students found schools that allowed them to do their teaching practice as volunteer work, but they still had challenges of readjustment and familiarising with the new environment.

Related to the rationalisation issue above is a situation where a significant number of Post Graduate Diploma in Education (PGDE) students were employed as primary school teachers. Some of these students had been teaching at secondary school but because of rationalisation, they were forcibly transferred to primary school. The PGDE programme is for secondary school teachers offering two optional teaching subjects at secondary school. In some cases even the programme coordinator did not give the student proper advice so that they arrange with the nearby secondary school for their teaching practice. Those who were advised accordingly made arrangements with their heads and the nearby secondary schools to have two days they are time tabled to teach at secondary school. This arrangement made student teachers overloaded since they still had their primary school class, but it was a better arrangement than simply teach at primary school and wait. One female student in Hwange became a victim of this scenario and had to defer her teaching practice assessment since she could not be assessed at primary school.

The PGDE programme is an in-service programme for university degreed graduates who have content of their subject areas but do not have teaching theory to help them teach effectively. The major challenge here was that some of these untrained degreed teachers have been teaching and producing good results for the past 20 or even more years. The headmaster and other members of staff see him/ her as one of their best teachers. Teaching this person new professional ways of teaching became very difficult. They argued they have been teaching and producing very good results through their 'bad ways'! Even their heads found it difficult to accept that these excellent teachers could be found wanting in terms of their teaching practice. Some of the students were fresh university degreed graduates who had not yet been offered any teaching post by the ministry. Although they had content of their subject areas, they were more like doing pre-service training since they were not attached to any 
institution. Some of them were offering voluntary service at nearby secondary schools, but the challenge was treating them the same as those already employed! Were they really being in-serviced?

There were cases of student teachers with posts of responsibilities like acting heads, deputy heads, sport masters, and so on. These student teachers were found to put much of their attention to these responsibilities at the expense of their teaching practice and studies. Files for most of these students were not up to standard. In addition, these students, especially headmasters, were under the mentorship of their subordinates. There was thus high degree of the subordinate doing the file for the boss and even awarding the boss undeserved high internal marks.

A related scenario was where the mentor simply had a diploma or certificate in teaching at secondary school. Most degreed in-service student teachers felt that these diploma holders were not qualified enough to supervise them. The qualified diploma holders also tended to have an inferiority complex, or simply 'á watch and see' attitude. In this situation the in-service degreed student teacher learn nothing from the mentorship relationship.

There were also issues of standardisation. Some supervisors seemed not properly oriented and in most cases tended to overlook important issues. Sometimes comments were not in tandem with the marks given. Usually supervisors would give distinction for work that does not deserve such high marks. In fact, some supervisors lack knowledge and experience of supervision. Hence, they ended up giving very high marks where they were not deserved. This did not help the student in his / her teaching practice. Related to this some programme coordinators simply developed their own assessment / measurement / supervision form different from the university tool. This development translated into serious variations in the allocation of marks and recommendations to students.

School culture also affected students' performance. Students at schools that seemed not committed to their work reflected the same attitude in their performance. You would tell the performance you are likely to meet just from looking at the environment and temperament of the school. The seniors or authorities within the school act as role models of student teachers.

Generally, documentation in rural areas schools was quite good when compared to the situation in urban areas schools. Perhaps this was because rural areas schoolteachers have more time at their schools since there are limited leisure and business activities in rural areas when compared to urban areas.

The timing and period assigned to supervision was not enough. In some regions, the number of students was too big to be finished within a week. Supervision was thus rushed without sitting down with the student and give him / her proper or helpful feedback. Two weeks would have been more helpful.

The Faculty of Arts and Education borrowed qualified and experienced supervisors from other Faculties. This created some difficulties for some of the supervisors when their Faculty or department leadership as though they were not aware of the exercise and made demands which could not be met when the supervisor was out on teaching practice supervision. In addition, it is important to note that the Faculty do not have a database of qualified supervisors to execute the programme. This situation affected the quality of supervision.

It is also important to note that the ZOU teaching practice programme has no vehicles attached to it. It depended on vehicles borrowed from directors. This affected the programme in that supervision was hurried up to meet deadlines of returning the borrowed vehicles.

Regions were also given the same time period to complete the supervision process, yet some regions have very high numbers of students in the programme. It would have been better had the authorities considered student population in deciding the time frame for completion of the supervision exercise in the regions.

There were also situations where students were not found at their stations having been sent to town or sports by authorities. Sometimes their files could not be located.

\subsection{Opportunities}

The visits by university academic supervisors did not only contribute to academic excellence, but also showed the university detractors that the university really meant business. In the past few years, when UNICEF sponsorship for professionalization of the untrained degreed teachers came, detractors argued that ZOU had no capacity to run the programme. Here ZOU was in the field with a whole range of not only qualified academics, but academic doctors and professors with experience ranging from secondary school and primary school teaching to teachers' colleges and university lectureship and teaching practice supervision. Thus, the teaching practice supervision exercise was also an opportunity to demonstrate that ZOU has more than the required capacity to train teachers. What remains is for ZOU to continue striving for the best and continue improve its operations so that it is miles ahead of its competitors.

The perception that ZOU not only operates from a distance, but a dubious and malfunctioning university was disproved. Most school heads and their deputies were graduates from the Zimbabwe Open University. These heads and many other teachers with qualifications from ZOU were happy to see ZOU visiting them at work. The inservice student teachers themselves were elated and felt proud of their university. They had been waiting in anxiety as they watched other in-service and pre-service student teachers from other universities and colleges being visited and supervised by their lecturers. In schools where heads and teaching staff had negative attitudes towards ZOU, the students had been reminded that ZOU would not visit them and thus their pending qualification was dubious. 
Now ZOU was there talking and pointing out their strength and weaknesses; empowering them together with their school based supervisors, and so forth. In fact, this was an opportunity to show the doubting Thomases that ZOU was good and the university of the day. Most headmasters were very appreciative and thus thanked ZOU for the good work. The supervision visits therefore assured ZOU of more students from referrals by the heads, their deputies, teachers and the in-service student teachers. In short, field assessment of in-service student teachers on teaching practice has proven to be a very effective motivational and teaching tool for the university.

Due to the current economic meltdown, the government is reluctant to give civil servants study leave. Nonetheless, the government still demands professionalization of teachers. Open and distance learning is the only viable solution to this dilemma. The teaching practice exercise thus helped the degreed teachers who had not yet embarked on their professionalization studies decide on what route to take. Given their circumstances, they are obviously going to take the ODL route.

\section{Conclusions and recommendations}

Using the above findings this study makes the following conclusions and recommendations:

- Teacher development / professionalization is highly contested with universities in the country competing for in-servicing the degreed teachers in the secondary schools. It is therefore recommended that the university mobilise it's qualified staff and appropriate resources so that it becomes the university of preference for the degreed teachers requiring in-service training.

- Teaching practice supervision requires well serviced 4 by 4 or land cruiser vehicles to negotiate the terrain and bumpy roads to reach the schools where our students are stationed. The university is therefore encouraged to establish an adequate and relevant pool of regional teaching practice vehicles.

- Some students were found to be misinformed on where they should do their teaching practice. Both the Faculty and Regional Centres should clearly and regularly communicate with their students on matters concerning their studies. Students should be told that their qualification is a secondary school teaching qualification. The teaching practice should therefore be done at a secondary school not a primary school.

- The Public Service Commission has been transferring in-service training degreed teachers to primary schools and sometimes even dismissing them from the civil service. There is need for authorities to negotiate with the PSC so that it neither transfer nor dismiss these students during their in-service training period.

- Some in-service student teachers had many years teaching experience and they felt that they knew their job well such that they continued with their unprofessional practices as long as they felt that they helped them attain their goal of making pupils pass examinations. Yet learning is not simply about passing examinations. The Faculty and Regional Centres should provide proper orientation to both the in-service student teachers and the host schools authorities.

- Some of the in-service student teachers had posts of responsibilities (acting heads) and this affected their performance. These students should be encouraged to relinquish these posts and de-role during their teaching practice period.

- There were difficulties in developing a mentor-mentee relationship in situations where the mentor was simply a diploma or certificate holder. There is need for proper orientation of both the mentee and mentor to ensure that the student gets enough and appropriate guidance.

- There were variations in supervision and assessment styles, measurement and evaluation of students. There is need to standardise the exercise through proper training of the academic supervisors so that they speak the same language.

- Some school cultures were found to negatively influence student performance and behaviour. There is need to properly train the student so that he /she becomes the instrument of change in the school.

- Supervision period was made the same for all region despite the fact that some regions had high volumes of students who sometimes covered a very wide geographical area. There is to rationalise this scenario accordingly with regions with more students being given more time and vehicles for the supervision exercise.

- Some students', especially those in urban areas, documentation was found to be very poor. Students without proper documentation should not pass the examinations.

- There were frictions between supervisors from other Faculties and their Faculty management. There should be clear communication between Faculties management and involvement of the management in the exercise.

- Some students were not found at their stations. Students should be advised to always leave their files their mentors or administration when travelling so that they are accessible when supervisors come for supervision.

- The university is also advised to exploit all the opportunities outlined in 6.2 above. 


\section{References}

Brookfield, S.D. (1986). Understanding and Facilitating Learning: A comprehensive analysis of principles and effective practices, Jossey-Bass, San Francisco, CA.

Daloz, L. (1986). Effective Teaching and Mentoring. San Francisco, CA: Jossey-Bass.

Dewey, J. (1938). Experience and education. New York. Collier.

Hansford, B., Tennent, L. and Ehrich, L.C. (2003). "Educational Mentoring: Is it worth the effort?" Education Research and Perspectives, Volume 30, Number 1.

Ehrich, L.C. and Hansford, B. (1999) Mentoring: Pros and cons for HRM. Asia Pacific Journal of Human Resources 37(3):92-107.

Kiggundu, E. and Nayimuli, S. (2009). Teaching practice: a make or break phase for student teachers. South African Journal of Education. 29: 345-358.

Kolb, D. (1984) Experiential Learning: Experience as the Source of Learning and Development. Prentice Hall, New Jersey.

Lave, J. and Wenger, E. (1991) Situated learning: Legitimate peripheral participation. Cambridge: Cambridge University Press.

Manion, L., Keith, R.B., Morrison, K. and Cohen, L. (2003). A guide to teaching practice. Available at http://www books.google.com/books. Accessed 18 October 2013

Marais, P. and Meier, C. (2004). Hear our voices: student teacher's experience during practical teaching. Africa Education Review 1: 220-233.

Menter, I. (1989). Teaching Stasis: Racism, sexism and school experience in initial teacher education. British Journal of Sociology of Education, 10: 459-473.

Musingafi, M.C.C., Mafumbate, R. (2014). Challenges and prospects for school based mentoring in the professional development of student teachers in Zimbabwe: Academics, mentees and mentors perceptions. Asian Journal of Social Sciences and Management Studies 1(2) pp. 32-39. ISSN 2313 - 7401 (online).

Ngidi, D.P. and Sibaya, P.T. (2003). Student teacher anxieties related to practice teaching. South African Journal of Education, 23: 18-22.

Perry, R. (2004). Teaching practice for early childhood. A guide for students. Available at http://www Routledge.com catalogues./0418114838.pdf. Accessed 18 October 2013.

Quick, G. and Sieborger, R. (2005). What matters in practice teaching? The perception of schools and students. South African Journal of Education, 25: 1-4.

Republic of South Africa, (2000). Norms and Standards for Educators. Government Gazette, No. 20844.

Schön, D.A. (1987) Educating the reflective practitioner. San Francisco: Jossey-Bass.

Sloboda, J. (1986). "Acquiring Skill" in A. Gellatly (Ed) The Skilful Mind: an introduction to cognitive psychology. Oxford University Press, Milton Keynes.

Tomlinson, P. (1995) Understanding mentoring: reflective strategies for school-based teacher preparation. Buckingham: Open University Press.

Villegas-Remers, E. (2003). Teacher professional development: an international view of the literature. UNESCO: International Institute for Educational Planning.

Vygotsky, L.S. (1978). Mind in Society. Cambridge, MA: Harvard University Press. 